\title{
Intrasexual Competition Shapes Men's Anti-Utilitarian Moral Decisions
}

\author{
Bastien Trémolière • Gwenaël Kaminski • \\ Jean-François Bonnefon
}

Published online: 4 November 2014

(C) Springer International Publishing 2014

\begin{abstract}
Killing someone in order to save several lives seems more morally acceptable to men than to women. We suggest that this greater approbation of utilitarian killings may reflect gender differences in the tolerance to inflicting physical harm, which are partly the product of sexual selection. Based on this account, we predicted that men may be less utilitarian than women in other conditions. In four studies, we show that men are more likely than women to make the anti-utilitarian (hypothetical) choice of causing three same sex deaths to save one opposite sex life; and that this choice is more likely when there are fewer potential sexual partners, more likely for heterosexual men and less likely if the female character to be saved no longer has reproductive value.
\end{abstract}

Keywords Intrasexual competition · Gender · Moral decision $\cdot$ Utilitarianism $\cdot$ Sexual preference

\section{Introduction}

Men and women do not always make the same moral choices. In particular, men are more likely to agree that killing someone can be morally acceptable provided that this death saves the lives of several other persons (Fumagalli et al. 2010; Lotto, Manfrinati, and Sarlo 2014; Youssef et al. 2012). In other

Electronic supplementary material The online version of this article (doi:10.1007/s40806-014-0003-3) contains supplementary material, which is available to authorized users.

B. Trémolière $(\bowtie) \cdot G$. Kaminski

Cognition, Langues, Langage, Ergonomie, University of Toulouse,

Toulouse, France

e-mail: bastien.tremoliere@gmail.com

J.-F. Bonnefon

Centre National de la Recherche Scientifique, Cognition, Langues,

Langage, Ergonomie, University of Toulouse, Toulouse, France words, men seem to be more utilitarian than women, more accepting of inflicting harm for the purpose of a greater good.

To the best of our knowledge, this gender difference has only been observed in cases in which utilitarianism implies to harm, and its causes are yet to be discovered. In this article, we suggest that this greater male utilitarianism is only one specific consequence of broader differences in male and female intrasexual competition. The main strength of our account is to make new predictions about the moral dilemmas for which men will become less utilitarian than women to the point of becoming anti-utilitarian.

Our sexual selection account is based on three claims which we develop and reference below: (a) men have better reproductive prospects when the operational sex ratio (OSR) in the population is biased toward females; (b) men have a greater propensity than women to inflict violence upon their sexual rivals; and (c) the aversion to utilitarian killings derive in part from the aversion to inflict violence.

Both sexes need to attract high quality mates and to outcompete rivals, and their difficulty in doing so is affected by the OSR in their population. When the OSR is female biased (more females than males), men have enhanced mating prospects, and the reverse is true for populations with a male-biased OSR (Emlen and Oring 1977; Kruger and Schlemmer 2009; Pollet and Nettle 2008). Accordingly, men have an evolutionary interest in augmenting the ratio of fertile women to men.

The advantages of a male-biased sex ratio for women are not as clear, given the potential dangers caused by having too many men in a population (Schacht et al. 2014). The two sexes, in any case, do not possess the same adaptations for outcompeting rivals. Because the parental investment of women (e.g., pregnancy, childbirth, and child care) is largely greater than that of men (Trivers 1972), their death would result in a larger fitness cost (Sear and Mace 2008). In part, because of this greater potential fitness cost, women tend to compete primarily with physically low-risk strategies, such as 
derogating their rivals (Campbell 2013; Campbell and Cross 2012; Vaillancourt 2013). In contrast, direct physical competition appears to have been a primary mechanism of sexual selection in men (Archer 2009; Hill et al. 2013; McDonald, Navarrete, and Van Vugt 2012; Puts 2010). Accordingly, sexual selection may have prepared men for physical conflict, both through physical traits such as greater upper body strength and through psychological traits such as a lower aversion to inflicting harm (Sell, Hone, and Pound 2012).

Let us now apply this framework to utilitarian dilemmas starting with a bare bone dilemma which does not specify the gender of the potential victims: "Would you kill one person if it saved the lives of three other persons?" Given that one's aversion to inflicting physical harm is known to predict one's moral aversion to utilitarian killings (Wiech et al. 2013), we would expect men (the more physically aggressive sex) to give more utilitarian responses, and this is indeed what has been generally observed in the literature, in which the gender of the victims has not been systematically manipulated. ${ }^{1}$

The true strength of the sexual selection account, though, is to make novel predictions about gender differences in moral thinking for novel versions of this classic moral judgment vignettes. In particular, the sexual selection account predicts that men can be less utilitarian than women, or even antiutilitarian (i.e., willing to kill several in order to save just one life), when specific conditions are met. More precisely, consider this genderized version of a sacrifice moral dilemma:

The genderized sacrifice dilemma Given the choice, would you decide to cause the death of three members of your own sex, or to cause the death of one member of the opposite sex?

For men, the dilemma translates as: Would you rather cause the death of three men (saving one woman), or cause the death of one woman (saving three men)? For women, the dilemma translates as: Would you rather cause the death of three women (saving one man), or cause the death of one man (saving three women) $?^{2}$ The sexual selection account assumes that men are more prepared than women to eliminate sexual rivals by the infliction of physical harm, especially in situations such as that described in the dilemma, which pose no physical risk to themselves. Accordingly, we predict that men will make the anti-utilitarian decision to cause the death of three men (same sex rivals) and let one woman live in the genderized dilemma, whereas women will make the utilitarian choice of saving the three instead of the one.

\footnotetext{
${ }^{1}$ In typical dilemmas, the harmful action is to cause the death of an individual whose sex is not specified, to save other individuals whose sex is not specified either.

${ }^{2}$ See the "Discussion" for data on the symmetrical genderized dilemma, in which one has a choice between causing the death of one same sex individual or of three opposite sex individuals.
}

In the rest of this article, we offer repeated evidence for this phenomenon, in online and offline studies, and we identify moderators and boundary conditions which are consistent with its sexual selection account. We reason that if male anti-utilitarianism in the genderized dilemma derives from sexual selection via intrasexual competition, then it should be especially strong in contexts where sexual resources are scarce (and intrasexual competition is fiercer Arnocky et al. 2014). Furthermore, and for the same reason, we expect antiutilitarianism to be lower for homosexual males and to disappear when the dilemma features a woman in their 50 s, who no longer has reproductive value.

\section{Methods}

All studies recorded the decision made by participants faced with our genderized dilemma: If they had to, would they prefer sacrificing three persons of the same sex as theirs, or one person of the opposite sex? Study 1 was conducted online and tested several dilemmas aimed at evoking different conditions of sexual scarcity. Study 2 replicated the main result of study 1 in a traditional offline sample. Study 3 controlled for the sexual preferences of participants. Study 4 manipulated the age of the characters in the dilemma. Online studies $(1,3$, and 4) were administered using the Qualtrics software, and their participants were drawn from a panel administered by the French RISC platform. Raw data for the four studies have been uploaded as Electronic Supplementary Material.

\section{Data Statement}

For all experiments, we report all measures, conditions, and data exclusions. The target sample sizes were 50, 100, 400, and 200 for Studies 1-4, respectively (see below for rationales). These targets were typically exceeded in just a couple of days of online data collection, in which case all participants were kept in the sample.

\section{Study 1}

Each participant $(25$ men and 32 women; age: $M=$ 30 years, $\mathrm{SD}=8.7)$ responded to three genderized dilemmas (see Electronic Supplementary Material). The three dilemmas took place in three different environments chosen to evoke increasingly scarce sexual resources: a large city, a remote rural location, and a spaceship.

\section{Study 2}

Students at the University of Toulouse (59 men and 48 women; age: $M=20$ years, s.d. $=3.2$ ) volunteered to participate. They responded to the spaceship scenario, which delivered 
the largest effect in study 1 . Study 2 involved double the number of participants as study 1 , in order to obtain a more precise assessment of the effect size.

\section{Study 3}

Participants (183 men and 332 women; age: $M=35$ years, s.d. $=15)$ responded to the spaceship scenario and indicated their sexual preference on a scale from 0 (totally homosexual) to 100 (totally heterosexual). A large sample was necessary to obtain responses from a sufficient number of homosexual participants.

\section{Study 4}

Participants ( 76 men and 173 women, age: $M=39$ years, s.d.= 15 ) were randomly assigned to the 30 -year group (all characters in the dilemmas were described as being 30 -year old) or the 50-year group (all characters in the dilemmas were described as being 50 -year old). They responded to the spaceship and remote island scenarios (introduced to extend our findings to at least one additional scenario). Because study 4 investigated a negative moderator of the effect first identified in study1, sample size was set as four times larger than that in study 1 .

\section{Data Analysis}

In all studies, data were analyzed by means of fitting a multiple logistic regression, predicting the likelihood of making the anti-utilitarian choice (killing three to save one), based on gender and an optional additional predictor (e.g., scarcity in study 1 , age of the characters in study 4). All predictors were considered fixed effect variables, except for participants (studies 1 and 4) and scenario (study 4), which were considered random effect variables. Planned contrast analyses were performed to examine the specific effects of age in studies 3 and 4. Statistical analyses were conducted using SAS.

\section{Results}

\section{Study 1}

Figure 1a displays the proportion of participants willing to sacrifice three same sex characters in order to save one character of the opposite sex. Men were more likely than women (odd ratio $=3.8,95 \%$ confidence interval $(\mathrm{CI})[1.3-10.8]$ ) to make that hypothetical choice, $F(1,110)=6.39, p=0.013$. Furthermore, men were more especially likely (12 men out of 25 , vs. 6 women out of 32) to make that choice in the spaceship scenario, in which mating opportunities were presumably the scarcest, $F(1,110)=3.96, p=0.049$.

Study 2

Figure $1 \mathrm{~b}$ displays the proportion of participants "willing" to sacrifice three same sex characters in order to save one character of the opposite sex, in the spaceship scenario, in studies 1-3. As shown in Fig. 1b, study 2 replicated the main effect of study 1: Men were more likely to make the anti-utilitarian choice ( 34 out of 59$)$ than women $(18$ out of 48$), F(1,105)=$ $4.5, p=0.036 ; \mathrm{OR}=2.3,95 \% \mathrm{CI}(1.1-5.1)$.

\section{Study 3}

For the purpose of analysis, participants were categorized as homosexuals (16 men and 7 women) if they rated themselves between 0 and 40 on the sexual preference scale, bisexuals ( 6 men and 10 women) between 40 and 60 , and heterosexuals (161 men and 315 women) between 60 and 100. Bisexual participants were excluded from further analysis. Heterosexual men were more likely than heterosexual women $(\mathrm{OR}=7.4$, $95 \% \mathrm{CI}[4.2-13.2])$ to make the anti-utilitarian choice, 121 men out of 161 vs. 110 women out of $315, F(1,474)=48.12$, $p<0.0001$. The 16 homosexual men differed markedly from the rest of the male sample: Only $19 \%$ made the antiutilitarian choice, compared to $75 \%$ of the heterosexual men (Fisher's exact test, $p<0.0001$ ).

\section{Study 4}

Figure 1c displays the proportion of participants willing to sacrifice three same sex characters in order to save one character of the opposite sex, as a function of the age of these fictional characters. An interaction effect revealed that the age of the characters had a strong effect on the responses of men, but not on the responses of women, $F(1,247)=4.9, p=0.027$. Men were more likely than women to make the anti-utilitarian choice (on average, 55 men out of 76 vs. 75 women out of 173) when the characters were in their $30 \mathrm{~s}, t(247)=4.16$, $p<0.0001 ; \mathrm{OR}=4.1,95 \% \mathrm{CI}[2.1-7.8])$, but not when the characters were in their $50 \mathrm{~s}$ (on average, 36 men out of $76 \mathrm{vs}$. 69 women out of 173), $t(247)=1.14, p=0.25$.

\section{Discussion}

Previous research showed that men accepted utilitarian killings to a greater extent than women: Men were more likely to accept that someone be killed in order to save several lives. We suggested that this effect might be due to gender differences in the tolerance to inflicting physical harm to sexual 
(A)

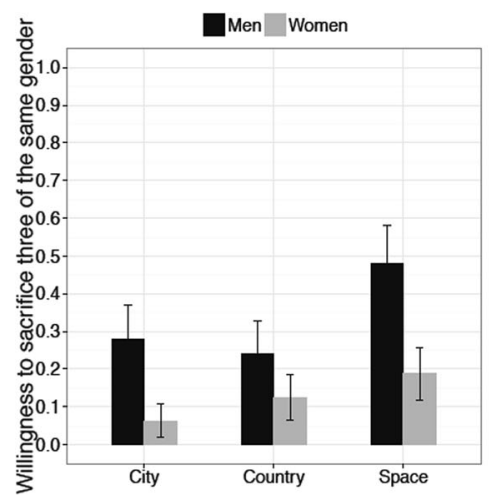

(B)

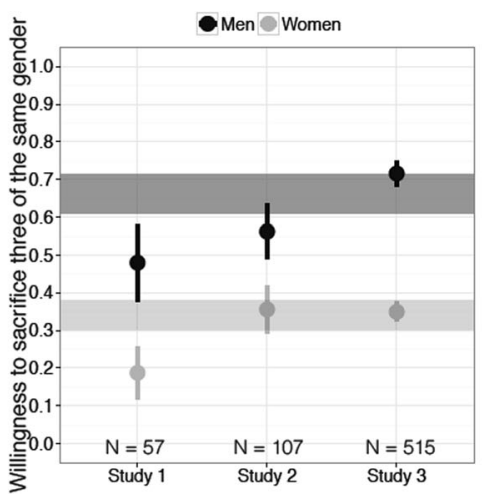

(C)

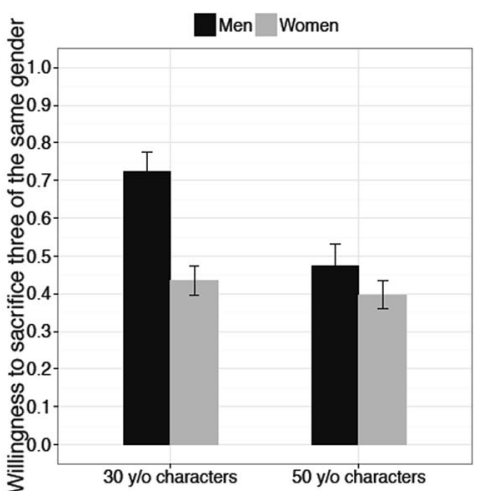

Fig. 1 Proportion of anti-utilitarian choices in the genderized dilemma for male and female participants. a In study 1, men are especially likely to make the anti-utilitarian choice in the spaceship scenario, where the mating opportunities are the fewest. b The spaceship scenario was used in comparable conditions in three studies, allowing for the computation of metaproportions of anti-utilitarian choices by men and women. The $95 \%$ confidence intervals for these two metaproportions are shown in dark grey and light grey, respectively. c In study 4, men were no longer more likely than women to make the anti-utilitarian choice, when this choice saved a woman past her reproductive years rivals. Based on this evolutionary account, we predicted that men could also be less utilitarian than women in the right conditions, and more specifically when presented with our genderized dilemma: kill three members of the same sex (saving one of the opposite sex), or kill one member of the opposite sex (saving three of the same sex)?

In four studies, we found repeated evidence for this prediction. As a rough summary of our main finding, we can consider the meta-proportion of anti-utilitarian choices in the spaceship scenario, which was used in comparable conditions in three studies (see Fig. 1b). This meta-proportion (computed with the metaprop function of the meta R package) was $66 \%$ for men (95\% CI [60-72]), and $34 \%$ for women (95\% CI [30-39]).

Because our genderized dilemma aimed at showcasing anti-utilitarian male judgments, we never gave participants the mirror-genderized dilemma where they would choose between killing three members of the opposite sex (saving one of the same sex), or kill one member of the same sex (saving three of the opposite sex). Nonetheless, our account straightforwardly predicts that this mirror version would not make a difference for women, while it would make men hyper-utilitarian. To quickly check this additional prediction, we gave this mirror dilemma to an online sample of 158 heterosexual men and 293 heterosexual women. The proportion of anti-utilitarian responses in this mirror version stayed at $33 \%$ for women (just as in the original version), but dropped to $5 \%$ for men.

Can cultural or social norms alone explain our findings? Perhaps. As captured by the "women and children first" rule of escape, men may be socially expected to give priority to saving the life of women. Data on interpersonal aggression also suggest the existence of a norm of chivalry, according to which male-on-female violence is perceived as especially unacceptable (Davidovic, Bell, Ferguson, Gorski, and
Campbell 2011; Felson and Feld 2009). The most compelling argument against this explanation of our findings comes from the effect of age in study 4 , in which men were no longer willing to sacrifice three men in order to save a woman in her 50 s. It is difficult to explain why a norm of chivalry would no longer apply to a woman older than 50, without appealing to additional ad hoc norms. An evolutionary account, though, easily explain why the life of a woman past her fertile years might be less of a priority for male participants.

Although we observed a large and robust difference between the responses of men and women, the proportion of women making the hypothetical choice to kill three women rather than one man remained puzzlingly high, at about one third. Across all studies, the only reliable moderator of this choice was the age of female participants. Anti-utilitarian choices were mostly made by younger, rather than older female participants (effect detected in study $4, t(471)=2.8$, $p=0.005 ; \mathrm{OR}=2.6,95 \% \mathrm{CI}[1.3-5.2]$ and marginal in study $3, t(247)=1.7, p=0.08)$, whereas age had no reliable effect on the responses of male participants. This is an interesting side result since it suggests that whereas men of all ages may fell prey to sexual selection effects on moral choices, these effects might be limited to women in their fertile years - which could, in turn, suggest that intrasexual rivalry plays a role in their responses. We will nevertheless refrain from speculating too much from an unpredicted finding whose full investigation would probably require to identify the traits and characteristics of the minority of women who make the anti-utilitarian choice.

Whereas age was the only predictor of female moral choices in our task, the moral choices of men were influenced by several moderators, all to be expected from a sexual selection account. Men were more willing to (hypothetically) eliminate other men in situations where mating opportunities were presumably scarce and competition presumably fiercer. 
Homosexual men were less willing to (hypothetically) eliminate other men, demonstrating that heterosexual interest was an essential component of the effect. Finally, men were no longer willing to eliminate other men if the woman to be saved was in her 50 s rather than in her 30 s and thus presumably no longer fertile.

All these results must be taken with caution. First, given our questionnaire methodology, participants might have responded on the basis of what they would condone or condemn in others rather than on the basis of what they would actually do by themselves. Second, the link between adult sex ratio, sexual competition, and aggressiveness might not to be as strong as previously believed (Schacht, Rauch, and Borgerhoff Mulder 2014). Third, homosexual men were only 16 in the convenience sample of study 3 . Fourth, the age of the woman to be saved was confounded in study 4 with the age of the men to be eliminated. Nonetheless, our pattern of results is consistent and suggestive: the moral choices of men, rather than simply indicating greater utilitarianism, may reflect the subtle workings of sexual selection and intrasexual competition. Under the circumstances typical of previous research, men appeared to be more utilitarian; but the same evolutionary account that explained this result also predicted the circumstances in which men would become anti-utilitarian. Future research may explore the applied relevance of these findings, in terms of the implicit value that male and female decisionmakers put on male and female lives, in contexts going from healthcare to warfare.

\section{References}

Archer, J. (2009). Does sexual selection explain human sex differences in aggression? Behavioral and Brain Sciences, 32(3-4), 249-266. doi: 10.1017/s0140525x09990951.

Arnocky, S., Ribout, A., Mirza, R. S., \& Knack, J. M. (2014). Perceived mate availability influences intrasexual competition, jealousy and mateguarding behavior. Journal of Evolutionary Psychology, 12(1), 45-64.

Campbell, A. (2013). The evolutionary psychology of women's aggression. Philosophical Transactions of the Royal Society, B: Biological Sciences, 368(1631), 20130078. doi:10.1098/rstb.2013.0078.

Campbell, A., \& Cross, C. (2012). Women and aggression. In T. K. Shackelford \& V. A. Weekes-Schakelford (Eds.), The Oxford handbook of evolutionary perspectives on violence, homicide, and war (pp. 197-217). New York: Oxford University Press. doi:10.1093/ oxfordhb/9780199738403.013.0012.

Davidovic, A., Bell, K., Ferguson, C., Gorski, E., \& Campbell, A. (2011). Impelling and inhibitory forces in aggression: sex-of-target and relationship effects. Journal of Interpersonal Violence, 26(15), 3098-3126. doi:10.1177/0886260510390953.

Emlen, S., \& Oring, L. (1977). Ecology, sexual selection, and the evolution of mating systems. Science, 197, 215-223.

Felson, R. B., \& Feld, S. L. (2009). When a man hits a woman: moral evaluations and reporting violence to the police. Aggressive Behavior, 35(6), 477-488. doi:10.1002/ab.20323.

Fumagalli, M., Ferrucci, R., Mameli, F., Marceglia, S., Mrakic-Sposta, S., Zago, S., et al. (2010). Gender-related differences in moral judgments. Cognitive Processing, 11(3), 219-226. doi:10.1007/s10339009-0335-2.

Hill, A. K., Hunt, J., Welling, L. L., Cárdenas, R. A., Rotella, M. A., Wheatley, J. R., \& Puts, D. A. (2013). Quantifying the strength and form of sexual selection on men's traits. Evolution and Human Behavior, 34(5), 334-341. doi:10.1016/j.evolhumbehav.2013.05. 004.

Kruger, D. J., \& Schlemmer, E. (2009). Male scarcity is differentially related to male marital likelihood across the life course. Evolutionary Psychology, 7(2), 280-28.

Lotto, L., Manfrinati, A., \& Sarlo, M. (2014). A new set of moral dilemmas: norms for moral acceptability, decision times, and emotional salience. Journal of Behavioral Decision Making, 27(1), 5765. doi:10.1002/bdm. 1782.

McDonald, M. M., Navarrete, C. D., \& Van Vugt, M. (2012). Evolution and the psychology of intergroup conflict: the male warrior hypothesis. Philosophical Transactions of the Royal Society, B: Biological Sciences, 367(1589), 670-679. doi:10.1098/rstb.2011.0301.

Pollet, T. V., \& Nettle, D. (2008). Driving a hard bargain: sex ratio and male marriage success in a historical US population. Biology Letters, 4(1), 31-33.

Puts, D. A. (2010). Beauty and the beast: mechanisms of sexual selection in humans. Evolution and Human Behavior, 31(3), 157-175. doi:10. 1016/j.evolhumbehav.2010.02.005.

Schacht, R., Rauch, K. L., \& Borgerhoff Mulder, M. (2014). Too many men: the violence problem? Trends in Ecology \& Evolution, 29(4), 214-222. doi:10.1016/j.tree.2014.02.001.

Sear, R., \& Mace, R. (2008). Who keeps children alive? A review of the effects of kin on child survival. Evolution and Human Behavior, 29(1), 1-18.

Sell, A., Hone, L. S., \& Pound, N. (2012). The importance of physical strength to human males. Human Nature, 23(1), 30-44. doi:10. 1007/s12110-012-9131-2.

Trivers, R. L. (1972). Parental investment and sexual selection. In B. Campbell (Ed.), Sexual selection and the descent of man 1871-1971 (pp. 136-179). Chicago: Aldine.

Vaillancourt, T. (2013). Do human females use indirect aggression as an intrasexual competition strategy? Philosophical Transactions of the Royal Society, B: Biological Sciences, 368(1631), 20130080. doi: 10.1098/rstb.2013.0080.

Wiech, K., Kahane, G., Shackel, N., Farias, M., Savulescu, J., \& Tracey, I. (2013). Cold or calculating? Reduced activity in the subgenual cingulate cortex reflects decreased emotional aversion to harming in counterintuitive utilitarian judgment. Cognition, 126(3), 364-372. doi:10.1016/j.cognition.2012.11.002.

Youssef, F. F., Dookeeram, K., Basdeo, V., Francis, E., Doman, M., Mamed, D., et al. (2012). Stress alters personal moral decision making. Psychoneuroendocrinology, 37(4), 491-498. doi:10.1016/ j.psyneuen.2011.07.017. 